\title{
Vagino-cutaneous fistula: unreported, under-reported or unheralded?
}

Ashwath Narayan Ramji*

Department of Surgery, Kempegowda Institute of Medical Sciences, Bangalore, Karnataka, India

Received: 06 April 2019

Accepted: 30 May 2019

\section{*Correspondence:}

Dr. Ashwath Ramji,

E-mail: drashwathramji@gmail.com

Copyright: (c) the author(s), publisher and licensee Medip Academy. This is an open-access article distributed under the terms of the Creative Commons Attribution Non-Commercial License, which permits unrestricted non-commercial use, distribution, and reproduction in any medium, provided the original work is properly cited.

\begin{abstract}
Fistulas are communicating tracts between two surfaces, linking structures and planes that should, under normal circumstances, not be in dialogue. They may be congenital or acquired and are most commonly associated with the gastrointestinal and ano-rectal territories, where they link two different organ systems internally, or track outwards, creating a communicating channel between the internal viscera and the skin surface. Vaginal fistulas on occasion result from perineal tears due to traumatic delivery, or less commonly, infection or non-healing of the episiotomy wound, and are of the rectovaginal or vesicovaginal variety. Very rarely, the channel from the vagina tracks to an opening in the skin. This is the report of a patient who developed the rare vagino-cutaneous fistula following a normal vaginal delivery with episiotomy, and review of the limited literature available about the peculiar entity, so rare that no previous reports of vagino-cutaneous fistulas developing after vaginal delivery with episiotomy could be found.
\end{abstract}

Keywords: Episiotomy, Fistula, Obstetric fistula, Perineal fistula, Vagino-cutaneous fistula, Vaginal fistula

\section{INTRODUCTION}

Fistula formation is a known complication of the episiotomy procedure. During the era of midline episiotomies, fistula-in-ano was the dreaded impediment, with causation linked to poor wound healing and unidentified or unrepaired lacerations of the grade 3-4 variety. ${ }^{1,2}$

They may also result from perineal trauma or delayed and obstructed labour. ${ }^{3}$

The incidence of the same has declined dramatically, corresponding to improvements in operative techniques, and only scattered occurrences of fistula-in-ano are associated with the mediolateral episiotomy. ${ }^{1,4}$
In this subset of patients, the risk factors for fistula formation include $3^{\text {rd }}$ and $4^{\text {th }}$ degree perineal tears, inflammatory bowel disease, tuberculosis, venereal disease and preceding perianal disease or pathology that compromise the local tissue integrity. ${ }^{5}$

More than 2 million women live with untreated obstetric fistulas in Asia and sub-Saharan Africa alone, with a global incidence of 100,000 new cases every year. ${ }^{6}$

Affected women suffer from unrelenting incontinence, foul-smelling discharge, pain, suppuration, dyspareunia, social isolation, shame and depression. ${ }^{3}$

The prevention and management of obstetric fistulas therefore is significant contributor to Sustainable 
Development Goal 3 (Improving Maternal Health) of the World Health Organisation (WHO). ${ }^{6}$

\section{CASE REPORT}

A 28-year-old female primigravida was referred form the Department of Obstetrics for evaluation of recurrent discharge from her left inner thigh. The patient had delivered her first child almost one year earlier via normal vaginal delivery at a tertiary center in a neighboring city, and her discharge summary mentioned lateral episiotomy had been performed in view of delayed labour.

As per the patient's anamnesis, she had the expected vaginal discharge and mild bleeding for about 5 days post the delivery, following which she was asymptomatic for the next 2-3 weeks. She then noticed soiling of her undergarments and located the offending source to be discharge from her left inner thigh.

The discharge was initially scanty and gradually progressed in volume. It was yellowish in colour, and occasionally bloodstained. She also had localised pain and severe dyspareunia, and recurrent episodes of low to moderate grade fever. Multiple attempts to implode the channel had been tried over the following months, with temporary, if any success.

Examination of the perineum revealed sutures in-situ along the left vaginal wall that were ineffectively holding together friable tissue which bled easily on touch (Figure 1). The sutured tissue was hyperemic, mildly edematous, mildly tender on manipulation and did not show any purulent material. The vestibule was otherwise normal.

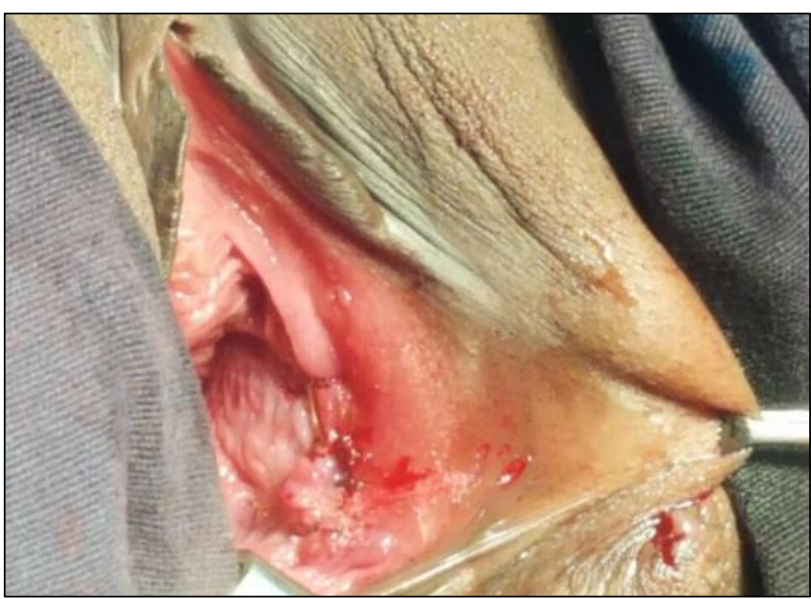

Figure 1: Sutures in situ amidst friable tissue.

Located along a linear track, the external opening was easily traced (Figure 2) to the medial aspect of the right thigh, along the groin crease, about one centimeter above the midpoint of the vestibule.
There were no other obviously visible external openings. Dye installation and probe insertion easily delineated the track, confirming a single, simple track without any branching or occult communications. Surrounding skin was normal, with no erythema or induration.

Ipsilateral regional lymph nodes were enlarged, discrete and non-tender. Manipulation of the surrounding tissue led to mild bleeding from the internal opening, but no frank discharge of pus was noted, however, swabs were taken for microbiological studies. The rest of the clinical examination was unremarkable. Routine pre-operative investigations done were normal.

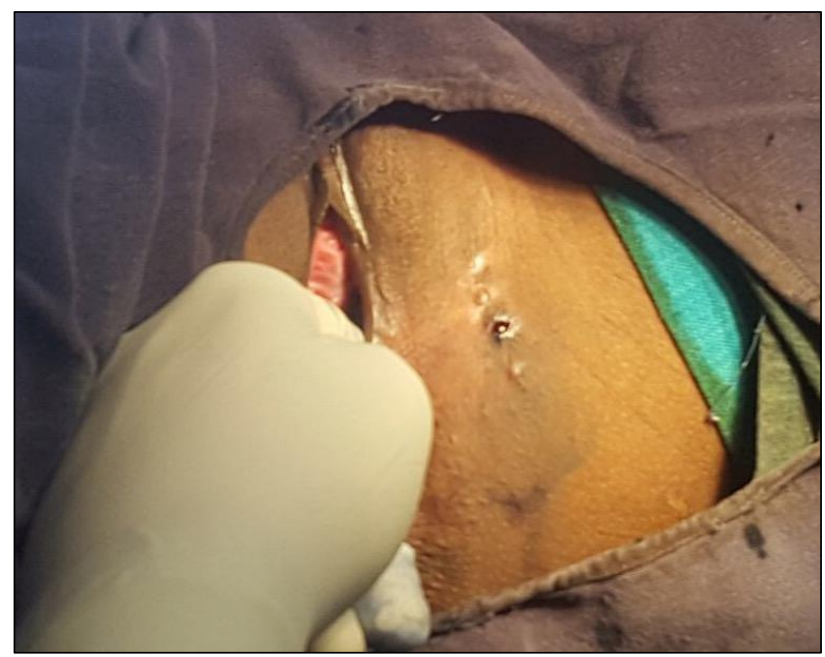

Figure 2: External opening.

Dye installation was performed intra-operatively to delineate the fistulous track, which was then excised under spinal anesthesia (Figures 3 and 4), with achievement of healthy margins.

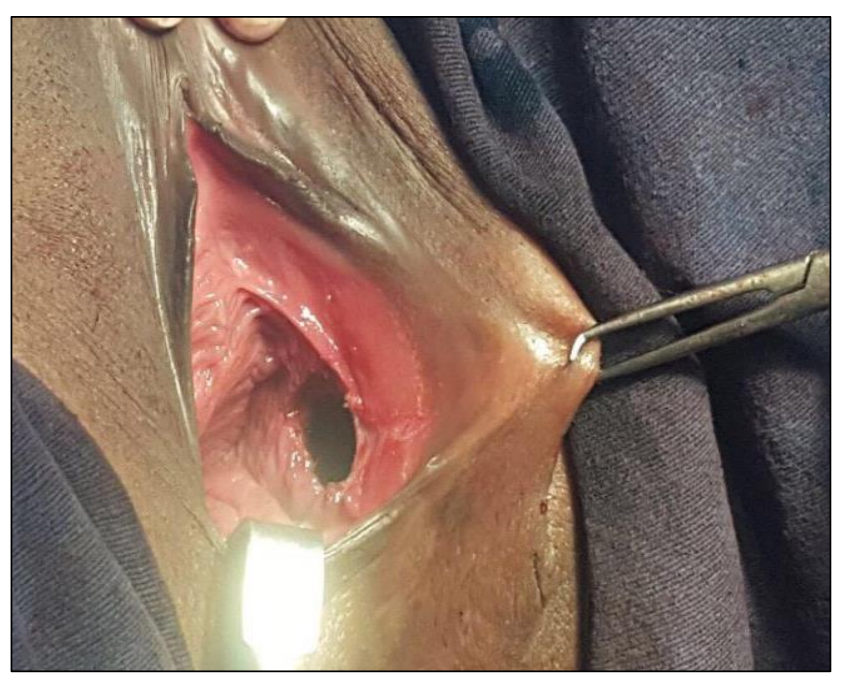

Figure 3: Post-track excision (vaginal aspect). 


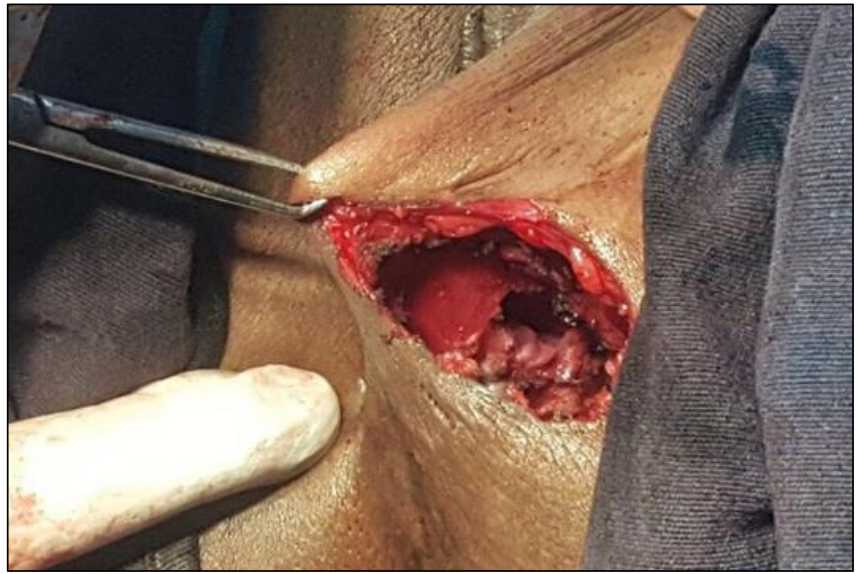

Figure 4: Post-track excision (cutaneous aspect).
In view of the local infection, complete approximation was abandoned, and the wound allowed to heal by secondary intention (Figure 4). The wound swab taken earlier showed growth of mixed flora with local commensals and contaminants, hence broad-spectrum antibiotic cover was continued and the patient was advised to perform daily sitz baths and ensure perineal hygiene. The post-operative period was uneventful, and at 3 months of follow-up, the wound had achieved complete healing.

\section{DISCUSSION}

Vaginal fistulas communicating with the urinary bladder or rectum are fairly common, however, fistulous extension into the skin is very rare.

Table 1: Risk factors for obstetric fistulas.

\begin{tabular}{|c|c|}
\hline General factors influencing wound healing & Vascularity \\
\hline & Nutritional status \\
\hline & Co-morbidities like diabetes mellitus \\
\hline & Estrogen deficiency States \\
\hline \multirow{5}{*}{ Compromised Tissue Integrity } & Previous pelvic surgery \\
\hline & Pelvic Irradiation \\
\hline & Local Infective focus \\
\hline & Local Malignancy \\
\hline & Connective tissue disease ${ }^{10}$ \\
\hline \multirow{3}{*}{ Mesh-related factors ${ }^{11}$} & Foreign body reactions \\
\hline & Erosions due to synthetic materials \\
\hline & Tension caused by tight sling placement \\
\hline \multirow{2}{*}{ Obstetric factors ${ }^{11}$} & Traumatic child birth \\
\hline & Macrosomia \\
\hline
\end{tabular}

PubMed Literature search using various combinations of appropriate keywords, Boolean operators, truncation, phrase searching and filters revealed just about 7 case reports pertaining to vagino-cutaneous fistulas, all of which developed as a consequence of surgery for stress urinary incontinence.

The risk factors for fistula formation are summarized in Table $1 .^{7,8,9}$

General factors associated with failure of wound healing also influence fistula formation (Table 1), including nutritional status, anemia, presence of irritant foreign bodies or infective foci. ${ }^{7-9}$

The risk is also higher when the tissue integrity was already compromised by prior malignancy, irradiation or connective tissue disease. ${ }^{10}$ Excessive trauma to the perineum due to prolonged labor, excessive and improper instrumentation, shoulder dystocia and macrosomia, due to pressure necrosis of the tissue, also hamper tissue healing.

Vaginocutaneous fistula arising following tension-freevaginal-tape placement for stress urinary incontinence (SUI) has been reported earlier by Sahin et al. ${ }^{7}$ The synthetic materials used in the sling are thought to induce an inflammatory response that can lead to erosion of the surrounding tissue. ${ }^{8}$ In their report, the patient had a wellformed inguinal abscess and was managed by drainage of the abscess, debridement of fistulous tissue and removal of the offending mesh. ${ }^{7}$

Similarly, one report documents vaginocutaneous fistula developing after Trans-Obturator Tape (TOT) surgery for urinary incontinence. ${ }^{12}$ Perianal surgery in the presence of compromised tissue integrity or hindrances to wound healing may propagate fistula formation, and has been 
noted with immunological conditions including Sjogren's Syndrome. ${ }^{10}$

Patients generally present with foul-smelling discharge from the vagina or surrounding skin, pain, dyspareunia and other constitutional symptoms like fever and malaise secondary to suppuration. ${ }^{13}$

The investigation includes MRI to localise and delineate the track and any branches or communications, which would guide the extent to debridement., ${ }^{72}$ Fistulogram, dye-installation with methylene blue and probe insertion are more economical albeit less sensitive techniques for achieving the same. ${ }^{11,12}$ In the case of the dye insertion technique, the colorant is introduced through the external opening and the internal opening(s) are identified by dye spillage.

Management is complete excision of the track by coring from outside inwards. ${ }^{7,12}$ Appropriate antibiotic cover and dressings are imperative to aid wound healing. ${ }^{12}$

In the case of vaginocutaneous fistulas associated with incontinence surgery, the patients were above 60 years of age and the onset of symptoms was several years after surgery. ${ }^{7,11,12}$

In continence surgery, synthetic material is used to reinforce weak endogenous tissue, eliciting a tissue reaction, which is a chronic process. ${ }^{11}$

Thus, appropriate non-inflammatory, non-irritant, nontoxic, non-antigenic material with pores large enough (>75 microns) to admit native tissue ingrowth and phagocyte movement should be selected, however, fistula formation following surgery for stress urinary incontinence has also been noted with the use of relatively inert material such as polypropylene tape. ${ }^{11,13}$

Vaginal estrogen supplementation may be beneficial in post-menopausal women. ${ }^{13}$ If rheumatologic disease is present, adequate control with immunomodulators is required for healing. ${ }^{10}$

\section{CONCLUSION}

Episiotomy has reduced the incidence of traumatic $3^{\text {rd }}$ and $4^{\text {th }}$ degree tears, and other complications associated with delayed and obstructed labour.

However, being an interventional procedure, it has inherent risk of complications including the development of obstetric fistulas, which can be agonizingly morbid conditions.

Conventional "risk versus benefit" discourse undoubtedly would advocate for an episiotomy to avoid worse outcomes including fetal hypoxia or death in conditions like macrosomia, shoulder dystocia or prolonged second stage of labour.
Diligent employment of episiotomy, using the sphinctersparing mediolateral incision under local anesthetic cover, ensuring optimal episiotomy repair and infectioncontrol practices are imperative to prevent the development of obstetric fistulas.

\section{Funding: No funding sources \\ Conflict of interest: None declared \\ Ethical approval: Not required}

\section{REFERENCES}

1. Barranger E, Haddad B, Paniel BJ. (2000) Fistula in ano as a rare complication of mediolateral episiotomy: Report of three cases. Am J Obstet Gynecol. 2000;182(3):733-4.

2. Rogers RG, Jeppson, PC. Current Diagnosis and Management of Pelvic Fistulae in Women. Obstet Gynecol. 2016;128(3):635-50.

3. Polan ML, Sleemi A, Bedane MM, Svjetlana L, Mark AM. Obstetric Fistula. Chapter 6. In: Debas HT, Donkor P, Gawande A, Dean TJ, Margaret EK, Charles NM. Essential Surgery: Disease Control Priorities. $3^{\text {rd }}$ Ed. Washington (DC): The International Bank for Reconstruction and Development / The World Bank. 2015;1.

4. Brown HW, Wang L, Bunker CH, Lowder JL. Lower reproductive tract fistula repairs in inpatient US women, 1979-2006. Int Urogynecol J. 2012;23(4):403-10.

5. Dorairajan G, Hima Bindu N (2014). Chronic nonhealing sinus manifesting in episiotomy scar: Hidden fistula-in-ano. Int Urogynaecol J. 2014;25(10):14413.

6. World Health Organization. 2019. 10 facts on obstetric fistula. [online] Available at: https://www.who.int/features/factfiles/obstetric_fistul a/en/

7. Sahin, A, Ilbey, Y, Sahin, N. Vaginocutaneous fistula and inguinal abscess presented 6 years after tension-free vaginal tape sling. Archivio Italiano Di Urologia E Andrologia. 2013;85(2):104-6.

8. Marques AL, Aparício C, Negrão L. Perineal cellulitis as a late complication of trans-obturator sub-urethral tape, Obtape. Int Urogynecol J Pelvic Floor Dysfunct. 2007;18(7):821-2.

9. Lowman J, Moore RD, Miklos JR. Tension-free vaginal tape sling with a porcine interposition graft in an irradiated patient with a past history of a urethrovaginal fistula and urethral mesh erosion: a case report. J Reprod Med. 2007;52(6):560-2.

10. Beksac K, Turgal M, Basaran D, Aran O, Beksac MS. (2014) Vaginoperineal Fistula as a Complication of Perianal Surgery in a Patient with Sjögren's Syndrome: A Case Report. Case Reports in Rheumatology. Volume 2014, Article ID 359605. Available at: http://dx.doi.org/10.1155/2014/359605.

11. Giles DL, Davila GW. Suprapubic-Vaginocutaneous Fistula 18 Years After a Bladder-Neck Suspension. Obstet Gynecol. 2005;105(5):1193-5. 
12. Maffiolini M, Asteria CR. A cutaneous-vaginal fistula and myositis of the obturator muscle following placement of a trans-obturator tape for stress incontinence. Euro J Obstet Gynecol Reprod Biol. 2010;149(2):225-6.

13. Abdallah A, Nisolle M, de Landsheere, L. Vaginocutaneous fistula and buttock abscess formation 7 years after polypropylene transobturator tape insertion. J Gynecol Obstet Human Repro. 2017;46(1):103-5.

Cite this article as: Ramji AN. Vagino-cutaneous fistula: unreported, under-reported or unheralded?. Int J Reprod Contracept Obstet Gynecol 2019;8:2932-6. 